ASTHMA

\title{
Initial starting dose of inhaled corticosteroids in adults with asthma: a systematic review
}

\author{
H Powell, P G Gibson
}

Thorax 2004;59:1041-1045. doi: 10.1136/thx.2004.023754

See end of article for authors' affiliations

......................

Correspondence to:

Professor P G Gibson,

Department of Respiratory

and Sleep Medicine,

Hunter Medical Research

Institute, John Hunter

Hospital, Locked Bag \#1,

Hunter Mail Centre,

Newcastle NSW 2310

Australia; mdpgg@mail

newcastle.edu.au

Received 24 January 2004

Accepted 24 June 2004
Background: Asthma guidelines vary in their recommendations for the initial dose of inhaled corticosteroid (ICS) in asthma. A systematic review of the literature was conducted to establish the optimal starting dose of ICS for asthma in adults.

Methods: Randomised controlled trials comparing two doses of the same ICS in adults with asthma and no concomitant inhaled or oral corticosteroid were assessed. Included trials were analysed according to the following ICS dose comparisons: high ( $\geqslant 800 \mu \mathrm{g} /$ day beclomethasone (BDP)) versus moderate $(400<800 \mu \mathrm{g} /$ day BDP) $(\mathrm{n}=7)$; moderate versus low $(<400 \mu \mathrm{g} /$ day BDP) $(n=6)$; step down versus constant dose $(n=4)$.

Results: Fourteen publications describing 13 trials were included in the review. Studies $(n=4)$ that compared a step down approach with a constant moderate/low dose of ICS found no difference in lung function, symptoms, or rescue medications between the two treatment approaches $(p>0.05)$. There was no difference in the change in morning peak flow after treatment with high compared with moderate dose ICS. When compared with low dose ICS, moderate dose ICS significantly improved morning peak flow (change from baseline WMD $11.14 \mathrm{l} / \mathrm{min}, 95 \% \mathrm{Cl} 1.34$ to 20.93 ) and nocturnal symptoms (SMD -0.29 , $95 \% \mathrm{Cl}-0.53$ to -0.06 ).

Conclusions: For patients with asthma who require ICS, starting with a moderate dose is equivalent to starting with a high dose and stepping down. The small non-significant benefits of starting with a high ICS dose are not of sufficient clinical benefit to warrant its use. Initial moderate ICS doses appear to be more effective than an initial low ICS dose. l: nhaled corticosteroids (ICS) form the basis of maintenance therapy in subjects with asthma ${ }^{1-3}$ in whom they target the airway inflammatory process and effectively reduce mortality and morbidity from asthma. ${ }^{45}$ While the efficacy of ICS in asthma is well established, ${ }^{6-8}$ dosing remains problematic. For some outcomes the dose-efficacy curve is relatively flat and more than $90 \%$ of the benefit is achieved at low doses of ICS (for example, fluticasone propionate $250 \mu \mathrm{g} /$ day). ${ }^{6}{ }^{10}$ However, in clinical practice, very high doses of ICS are frequently prescribed ${ }^{11}$ and there are now reports of significant side effects including acute adrenal crises with high dose ICS. ${ }^{12}$ In addition, undertreatment of asthma could result when inadequate doses of ICS are used.

Asthma guidelines recommend that maintenance ICS be given at the lowest effective dose according to the severity of the condition. ${ }^{1-3}$ However, the optimal starting dose of ICS in asthma has not been established. This is an important issue since there is concern that patients started on an initial high dose of ICS may continue to receive this dose in the long term and therefore be exposed to unnecessarily high ICS doses. Asthma guidelines vary in their recommendations for starting ICS. The GINA guidelines recommend a wide range of starting doses ranging from 200 to $1000 \mu \mathrm{g}$ beclomethasone equivalent per day, ${ }^{2}$ the Australian guidelines recommend starting with a high dose of ICS and then reducing the dose (step down), ${ }^{3}$ while the British Thoracic Society/Scottish Intercollegiate Guideline Network (BTS/SIGN) guidelines and the New Zealand guidelines recommend starting with moderate to low doses of ICS. ${ }^{13}$ The aim of this systematic review and meta-analysis was to establish the optimal starting dose of ICS for adults with asthma.

\section{METHODS}

A Cochrane systematic review was performed. ${ }^{14}$ Included studies were randomised controlled trials of two different doses of the same ICS, for a minimum treatment period of 4 weeks, in adults with asthma who had no concomitant inhaled or oral corticosteroid therapy and where relevant asthma outcomes were reported. Studies were only included where participants were steroid naïve or ICS free for more than 4 weeks. This report addresses studies conducted in adults only. Paediatric studies are reviewed in an electronic version of this review. ${ }^{14}$

\section{Identification of studies}

Studies were identified from the Cochrane Airways Group's controlled clinical trials register derived from MEDLINE, EMBASE, CINAHL, hand searched respiratory journals and meetings abstracts for papers published before September 2002. The search terms used were (asthma OR wheez*) AND (step* $^{*}$ OR high* dose OR low ${ }^{*}$ dose) AND (inhaled corticoster* OR beclometh* OR triamcin* OR flutic* OR budes* $^{*}$ OR betameth ${ }^{*}$ OR flunis* OR cicles* OR momet $\left.{ }^{*}\right)$. Full text versions of the relevant papers were obtained and their bibliographic lists hand searched for additional articles.

\section{Validity assessment}

The full text version of each potentially relevant article was obtained and assessed by two independent reviewers. Each article was assessed for inclusion/exclusion criteria, methodological quality, and data extraction was performed. Disagreement on eligibility for inclusion was resolved by consensus. Agreement was 94\%, kappa 0.88. Methodological quality was assessed using the Jadad scale ${ }^{15}$ and also using the Cochrane method, which assessed the adequacy of 
randomisation and concealment of allocation. Authors were contacted to verify and provide further information about methodological approaches and outcomes data.

\section{Analysis of data}

The relative risk (RR) with 95\% confidence intervals was calculated for dichotomous outcomes. For continuous outcomes using different units of measure, a standardised mean difference (SMD) and 95\% confidence interval was calculated using a fixed effects model. For continuous outcomes using the same unit of measure, the weighted mean difference (WMD) was calculated. Significance was accepted at $\mathrm{p}<0.05$. The pooled results were tested for heterogeneity using a $\chi^{2}$ test with appropriate degrees of freedom. Outcomes were analysed according to delivery device, duration of treatment, and ICS type.

Primary comparisons were made and determined by the strength of the ICS dose and the type of intervention, step down or constant dose being compared. ICS dose and dose equivalence were classified according to the BTS guidelines ${ }^{1}$ as (a) high dose $(\geqslant 800 \mu \mathrm{g} /$ day beclomethasone (BDP) equivalent); (b) moderate dose (400-800 $\mu \mathrm{g} /$ day BDP); (c) low dose $(<400 \mu \mathrm{g} /$ day $\mathrm{BDP})$ and dose equivalence for BDP:budesonide as 1:1 ratio and BDP:fluticasone as 2:1 ratio. The use of dry powder inhalers or metered dose inhalers with or without a spacer for delivery of ICS was considered clinically equivalent. ${ }^{1}$

\section{RESULTS}

\section{Included studies}

Fourteen publications describing 13 parallel group randomised controlled trials met the inclusion criteria for the review (table 1). ${ }^{16-29}$ Budesonide (BUD) doses were compared in nine studies, fluticasone (FP) in three, and BDP in one. Seven studies compared high dose ICS with moderate dose ICS $(\mathrm{n}=1579)$, six compared moderate dose ICS with low dose ICS $(n=1140)$, and four studies compared a step down dose with a constant ICS dose regimen (starting with a high dose and back titrating to either a moderate or low dose $(n=1197))$. Two studies had three dosage arms of high, moderate and low dose ICS 2229 and were included in both the high $v$ moderate and moderate $v$ low dose ICS comparisons. Two studies that were included in the step down comparison were also included in the high $v$ moderate comparison using outcome data collected before stepping down the high dose ICS at 4 and 6 weeks, respectively. ${ }^{16}{ }^{17}$

Treatment periods ranged from a minimum of 4 weeks to 36 weeks, with the majority of studies $(n=9)$ conducted over a 4-12 week period. A dry powder inhaler (DPI) was used to deliver ICS in seven studies. Four studies used a metered dose inhaler (pMDI) with one of these also using a spacer device. Two studies did not state the method of ICS delivery. Methodological quality was good for the majority of studies (table 1). Twelve studies (92\%) were double blind and, using the Jadad system, $85 \%$ of the studies scored three or higher. Outcomes reported consistently in all three comparisons included lung function, symptoms, rescue medication use, and withdrawal due to adverse events.

\section{Participants}

Asthma was most frequently diagnosed by doctor's diagnosis, objective lung function, or American Thoracic Society criteria. Six studies included mild to moderate asthmatics, mild asthma was represented in two studies, moderate asthma in two studies, and two studies included participants with moderate to severe asthma. ${ }^{27}{ }^{29}$ In one study the level of asthma severity was unable to be determined. The characteristics of the participants are shown in table 2 .

\section{High versus moderate dose ICS}

A meta-analysis of the change in morning peak flow (PEF, l/min) from baseline found a non-significant improvement in favour of high dose ICS (WMD 5.72; 95\% CI - 1.56 to 13.00; fig 1). The $95 \%$ confidence intervals of the effect size excluded a clinically important change in PEF. One additional study ${ }^{20}$ found no treatment effect. Asthma symptoms were reduced in two studies with no significant difference between the treatment groups. ${ }^{24} 29$ One study only reported significant dose response relationships for symptom scores but not in a form that could be used for meta-analysis. ${ }^{21} 22$ There was no significant difference between high or moderate dose ICS for the change in daytime or night time symptom scores when the results of two studies (reporting symptom scores on the same 0-3 scale) were pooled in a meta-analysis (table 3 ). There was no significant difference

Table 1 Characteristics of included studies

\begin{tabular}{|c|c|c|c|c|c|c|c|c|}
\hline Study & Quality* & Design & $\begin{array}{l}\text { No enrolled/ } \\
\text { no completed }\end{array}$ & ICS type & Dose ( $\mu \mathrm{g} /$ day) & $\begin{array}{l}\text { Duration } \\
\text { (weeks) }\end{array}$ & $\begin{array}{l}\text { Delivery } \\
\text { device }\end{array}$ & Comparison \\
\hline Campbell $^{16}$ & $4 \mathrm{~B}$ & Parallel & $682 / 454$ & BUD & $800-400$ v 400 & 24 & DPI & $\begin{array}{l}\text { Step down } v \\
\text { constant/high } v \\
\text { moderate }\end{array}$ \\
\hline Chanez $^{17}$ & $4 \mathrm{~A}$ & Parallel & $169 / 137$ & BUD & $1600-200$ v 400 & 16 & DPI & $\begin{array}{l}\text { Step down } v \\
\text { constant/high } v \\
\text { moderate }\end{array}$ \\
\hline Jatakanon $^{18}$ & $3 B$ & Parallel & $22 / 21$ & BUD & $400 \vee 100$ & 4 & DPI & Moderate $v$ low \\
\hline Lorentzson $^{19}$ & $3 B$ & Parallel & $104 / 103$ & BUD & $400 \vee 200$ & 6 & $\mathrm{pMDI}$ & Moderate $v$ low \\
\hline Majima $^{20}$ & $1 \mathrm{~A}$ & Parallel & $17 / N S$ & BDP & 800 v 400 & 8 & NS & High $v$ moderate \\
\hline Miyamoto $^{21} 22$ & $5 \mathrm{~A}$ & Parallel & $267 / 224$ & BUD & 800 v 400 v 200 & 6 & DPI & $\begin{array}{l}\text { High } v \text { moderate/ } \\
\text { moderate } v \text { low }\end{array}$ \\
\hline Noonan ${ }^{23}$ & $3 B$ & Parallel & $138 / 119$ & FP & $200 \times 100$ & 8 & $\mathrm{pMDI}$ & Moderate $v$ low \\
\hline $\mathrm{O}^{\prime}$ Byrne $^{24}$ & $4 \mathrm{~A}$ & Parallel & $57 / 39$ & BUD & 800 v 400 & 16 & $\mathrm{pMDI}$ & High $v$ moderate \\
\hline Pedersen $^{25}$ & $2 B$ & Parallel & $85 / 53$ & BUD & $1600 \vee 400$ & 36 & NS & High $v$ moderate \\
\hline Pirozynski ${ }^{26}$ & $3 B$ & Parallel & $262 / \mathrm{NS}$ & BUD & $800-200$ v 200 & 12 & DPI & $\begin{array}{l}\text { Step down } v \\
\text { constant }\end{array}$ \\
\hline Sheffer $^{27}$ & $3 B$ & Parallel & $307 / 294$ & FP & $200 \vee 100$ & 12 & $\mathrm{pMDI}$ & Moderate $v$ low \\
\hline van der Molen ${ }^{28}$ & $3 B$ & Parallel & $84 / 73$ & BUD & $800-200$ v 200 & 12 & DPI & $\begin{array}{l}\text { Step down } v \\
\text { constant }\end{array}$ \\
\hline Wasserman $^{29}$ & $3 B$ & Parallel & $331 / 256$ & FP & $500 \vee 200 \vee 100$ & 12 & DPI & $\begin{array}{l}\text { High } v \text { moderate/ } \\
\text { moderate } v \text { low }\end{array}$ \\
\hline
\end{tabular}


Table 2 Summary of characteristics of participants in included studies

\begin{tabular}{|c|c|c|c|c|}
\hline Study & Age (mean (SD) or range) & Asthma diagnosis & Severity & Previous ICS use \\
\hline Campbell $^{16}$ & $33.5(13.8) / 33.3(15.6)$ & Documented diagnosis asthma & Excluded if $<60 \%$ predicted PEF & No ICS \\
\hline Chanez $^{17}$ & 38 (18-70 eligible range) & $\begin{array}{l}\text { PEF diurnal variation }>20 \% \text {, } \\
>12 \% \mathrm{FEV}_{1} \text { reversibility }\end{array}$ & $\begin{array}{l}\text { Mean FEV } 174 \% \text { predicted, } \\
\text { uncontrolled at enrolment }\end{array}$ & $\begin{array}{l}\text { No current ICS use. } 50 \% \\
\text { previous ICS use }\end{array}$ \\
\hline Jatakanon $^{18}$ & $29(2.4) / 31(1.2)$ & $\begin{array}{l}\text { Doctor diagnosis, objective lung } \\
\text { function ( } \mathrm{PC}_{20} \text { methacholine) }\end{array}$ & $\begin{array}{l}\mathrm{FEV}_{1}>80 \% \text { predicted. Mean } \\
\mathrm{FEV}_{1} 91.5 \% / 92.4 \% \text { predicted }\end{array}$ & ICS naïve \\
\hline Lorentzson $^{19}$ & 32 & NS & Mean PEF $75 \%$ predicted & No ICS \\
\hline Majima $^{20}$ & $45.3 / 43.3$ & $\begin{array}{l}\text { Objective lung function according } \\
\text { to Japanese Allergy Association }\end{array}$ & Stated mild to moderate asthma & $\begin{array}{l}\text { No ICS }>2 \text { months before } \\
\text { study }\end{array}$ \\
\hline Miyamoto $^{2122}$ & $\begin{array}{l}50.4(15) / 47.8(15.9) / \\
50.9(15.5)\end{array}$ & NS & Mild $62 \%$; moderate $37 \%$; severe $1 \%$ & $\begin{array}{l}\text { No ICS }>1 \text { month before } \\
\text { study }\end{array}$ \\
\hline Noonan $^{23}$ & $29(12-59)$ & ATS criteria & Mean $\mathrm{FEV}_{1} 73 \% / 76 \%$ predicted & No recent ICS \\
\hline $\mathrm{O}^{\prime}$ Byrne ${ }^{24}$ & $37 / 32$ & Objective lung function & Stated mild asthma & No ICS in past 3 months \\
\hline Pedersen $^{25}$ & $46.1(11.2) / 46.8(12.5)$ & ATS criteria & $\begin{array}{l}\text { Mean (SD) FEV } 170.7(14.2) \% / 78.8 \\
\text { (19.8)\% predicted }\end{array}$ & No ICS \\
\hline Pirozynski ${ }^{26}$ & 36 & NS & Mean $\mathrm{FEV}_{1} 82.3 \%$ predicted & No ICS \\
\hline Sheffer ${ }^{27}$ & $28(12-72) / 30(12-63)$ & Objective lung function & $\begin{array}{l}\text { Inclusion criteria } \mathrm{FEV}_{1} 45-75 \% \\
\text { predicted }\end{array}$ & No ICS in past month \\
\hline van der Molen ${ }^{28}$ & $31.3(10.8) / 32.0(8.1)$ & $\begin{array}{l}\text { Objective lung function (defined } \\
\text { by Dutch College for General } \\
\text { Practitioners) }\end{array}$ & $\begin{array}{l}\text { Not stated but inclusion criteria } \mathrm{FEV}_{1} \\
>50 \% \text { predicted }\end{array}$ & No ICS in past 2 months \\
\hline Wasserman ${ }^{29}$ & $29 / 27 / 29$ & ATS criteria & $\begin{array}{l}\text { Inclusion criteria } \mathrm{FEV}_{1}, 50-80 \% \\
\text { predicted }\end{array}$ & No ICS in past month \\
\hline
\end{tabular}

between ICS doses in rescue medication during the day or night (table 3).

\section{Moderate versus low dose ICS}

There was a significant improvement in morning PEF from baseline in favour of the moderate dose ICS group (WMD 11.14; 95\% CI 1.34 to 20.93; fig 1). Night time symptom score and mean number of wakenings also reached significance favouring a moderate dose ICS ( SMD $-0.29 ; 95 \%$ CI -0.53 to -0.06 ; table 3 ). There was no significant difference between moderate and low dose ICS for other symptom scores, mean symptom free days, or change in score from baseline. There was a non-significant reduction in rescue $\beta$ agonist use for moderate dose ICS (table 3), and one additional study reported no difference from baseline between moderate and low dose ICS in reduction in day or night $\beta$ agonist use. ${ }^{19}$

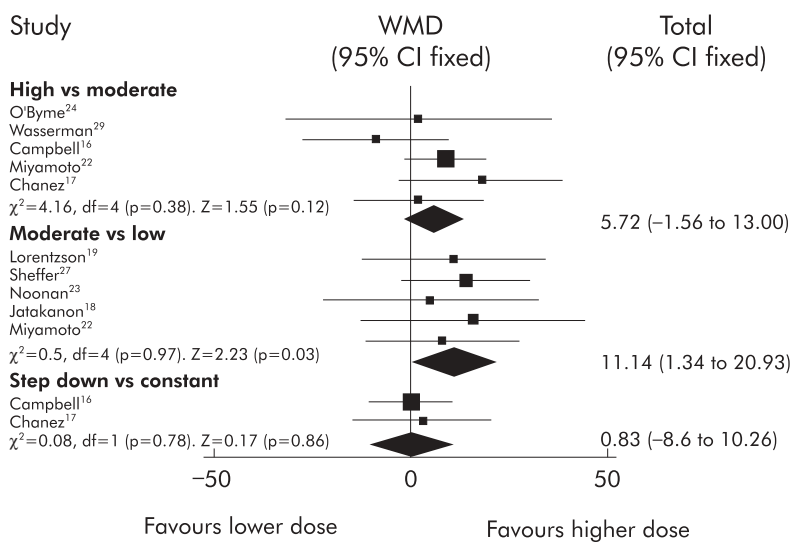

Figure 1 Effect of initial asthma treatment with high versus moderate dose ICS, moderate versus low dose ICS, and step down versus constant dose ICS on the change in morning peak expiratory flow from baseline. Weighted mean difference (WMD) for individual trials. $\chi^{2}$ refers to test for heterogeneity across different trials. $Z$ is the test statistic for weighted mean difference. WMD for individual trials is represented by squares and for total for each comparison (diamond =WMD 95\% CI). Results are reported as $\mathrm{I} / \mathrm{min}$.

\section{Step down versus constant dose ICS}

There was no significant difference between a step down ICS dose and constant dose ICS in the change in morning PEF ( $1 / \mathrm{min}$ ) from baseline in adults (WMD 0.83, 95\% CI -8.6 to 10.26; fig 1). Overall, there was no significant difference in symptoms between the two treatment approaches. Symptoms improved with no significant difference between the groups in one study ${ }^{26}$ and there was no significant difference between treatment groups when the results for night time symptom score were pooled in a meta-analysis (table 3). Two trials reported a reduction in $\beta$ agonist use for both treatment groups ${ }^{26} 28$ with no difference between the two groups (table 3 ).

\section{Withdrawal due to adverse events}

Withdrawal due to adverse events was reported in two studies comparing high and moderate dose ICS, ${ }^{21} 2229$ one study comparing moderate and low dose ICS, ${ }^{21}{ }^{22}$ and two studies comparing a step down dose with constant dose ICS. ${ }^{16}{ }^{17}$ There was no significant difference between treatment groups in the proportion of participants withdrawing due to an adverse event in the pooled results for each comparison.

\section{Subgroup analysis}

Further analyses by delivery device, duration of treatment, and ICS type found no significant effect for all outcomes (data not shown). ${ }^{14}$ However, these analyses may have been limited by the small size and number of studies.

\section{DISCUSSION}

This systematic review examined the results of 13 randomised controlled trials comparing initial ICS doses in asthma. The search was extensive and included all known published data. The meta-analysis supports the BTS/SIGN recommendation of using low to moderate doses of ICS as initial treatment for adults with asthma. We also evaluated the effects of starting ICS at a high dose (with or without a subsequent step down) compared with starting with a moderate or low dose ICS, and found no benefit of the step down approach when used as initial treatment. ICS step down (back titration) has an important place in determining maintenance ICS doses in asthma, however. 


\begin{tabular}{|c|c|c|c|c|}
\hline Comparison & $\begin{array}{l}\text { Outcome (change } \\
\text { from baseline) }\end{array}$ & $\begin{array}{l}\text { Sample size } \\
\text { (no of studies) }\end{array}$ & Statistic & $\begin{array}{l}\text { Effect size } \\
(95 \% \mathrm{CI})\end{array}$ \\
\hline \multicolumn{5}{|c|}{ High $v$ moderate } \\
\hline & PEF am (I/min) & $1117(5)$ & WMD & $5.72(-1.56$ to 13.00$)$ \\
\hline & Symptom score (night) & $800(2)$ & WMD & $0.02(-0.06$ to 0.10$)$ \\
\hline & Rescue medications (night) & $788(2)$ & WMD & $-0.03(-0.12$ to 0.05$)$ \\
\hline \multicolumn{5}{|c|}{ Moderate $v$ low } \\
\hline & PEF am (I/min) & $411(5)$ & WMD & $11.14(1.34 \text { to } 20.93)^{*}$ \\
\hline & Symptom score (night) & $285(3)$ & SMD & $-0.29(-0.53 \text { to }-0.06)^{*}$ \\
\hline & Rescue medications & $230(3)$ & WMD & $-0.35(-0.99$ to 0.29$)$ \\
\hline \multicolumn{5}{|c|}{ Step down $v$ constant } \\
\hline & PEF am (I/min) & $643(2)$ & WMD & $0.83(-8.60$ to 10.26$)$ \\
\hline & Symptom score (night) & $645(2)$ & WMD & $0.06(-0.04$ to 0.15$)$ \\
\hline & Rescue medications (night) & $643(2)$ & WMD & $-0.04(-0.13$ to 0.05$)$ \\
\hline
\end{tabular}

In view of the differing guideline recommendations and the frequent prescription of high dose ICS with subsequent significant side effects, it is important to establish the optimal starting dose for ICS in asthma. It has previously been established that low to moderate ICS doses are highly effective as maintenance treatment for asthma. ${ }^{6}{ }^{10}$ We have extended these observations to examine the efficacy of differing ICS doses as initial treatment. In most of the studies included in this review the efficacy was shown in both treatment arms for the majority of outcomes and there was no clear benefit for starting at a high ICS dose. A review of the seven studies that compared a constant high dose ICS with a moderate dose ICS showed that there was a nonsignificant improvement in the change in morning PEF from baseline. The upper $95 \%$ confidence interval of the effect size was $13 \mathrm{l} / \mathrm{min}$, which is less than a clinically significant change in PEF. This suggests that, although there was a trend for a benefit of high dose ICS, it is unlikely to be clinically significant even with further studies. No differences were found between commencing with high or moderate dose ICS for asthma symptoms or rescue medication use. The small non-significant benefit in lung function needs to be considered against the risks of increased side effects with the use of constant high dose ICS. ${ }^{6}{ }^{10}$ One particular concern is that, unless patients attend for regular medication review, the initial dose prescribed becomes the long term maintenance dose. This could explain the ongoing use of very high ICS doses, even though most guidelines recommend back titration. Starting treatment with a moderate dose should minimise this problem.

For moderate dose ICS there was a significant improvement in the change in morning PEF from baseline and nocturnal symptoms in comparison with low dose ICS. There were also non-significant improvements in the reduction of rescue medication use from baseline, suggesting a superior effect for moderate dose ICS.

The practice of starting with high dose ICS to gain control of asthma and then stepping down to a moderate or low maintenance dose is recommended in some asthma management guidelines. ${ }^{3}$ When we reviewed the four studies that compared this practice with a constant moderate or low ICS dose, we found no significant benefit in the effect on lung function, symptoms, or rescue medications. These results suggest that constant ICS doses have similar clinical efficacy to the more complex regimen of high ICS doses followed by a step down. One reason for considering initial high dose therapy is to obtain rapid symptom control. It is likely that this can be achieved by the use of ICS in combination with a long acting $\beta_{2}$ agonist (LABA). ${ }^{30}$ A comparison of initial asthma treatment with ICS versus a combination of ICS and LABA is the subject of a current systematic review.

This review was limited to the major outcomes including lung function and symptoms that were reported in the included studies. The analyses were also restricted to small numbers of studies of differing duration. However, there was a consistency in the reported results for the main outcomes across the studies. Analysis of inflammatory markers and exacerbations was not possible due to the lack of reporting of these outcomes. An analysis of airway hyperresponsiveness tended to support a benefit from higher ICS doses, but data were insufficient to permit meta-analysis. ${ }^{14}$ Future research could establish whether this is a true effect and whether it relates to control of inflammation or other aspects of airway pathology in asthma (such as remodelling).

In conclusion, the results of this review support initiating asthma treatment for mild to moderate asthmatics with low to moderate doses of ICS at a constant dose. The small nonsignificant benefits of commencing with a high dose of ICS are not of sufficient clinical benefit to warrant routine use when compared with moderate or low dose ICS. An initial moderate ICS dose appears to be more effective than an initial low ICS dose. Starting ICS at a constant moderate or low dose is equally efficacious to starting at a high dose and then stepping down.

\section{ACKNOWLEDGEMENTS}

The authors thank Toby Lasserson, Karen Blackhall, Jo Picot and Chris Cates from the Cochrane Airways Review Group for their assistance with this review and Dr B Volovitz, Dr W B Hofstra, Dr M J Visser and Dr O Selroos for Dr Miyamoto for providing information regarding their studies.

\section{Authors' affiliations \\ H Powell, Department of Respiratory and Sleep Medicine, Hunter Medical Research Institute, John Hunter Hospital, Newcastle, NSW 2310, and Cooperative Research Centre for Asthma, Camperdown, NSW 2050, Australia \\ P G Gibson, Department of Respiratory and Sleep Medicine, John Hunter Hospital, Hunter Medical Research Institute, Newcastle, NSW 2310, Australia}

Financial support was provided by the Cooperative Research Centre for Asthma.

\section{REFERENCES}

1 British Thoracic Society/Scottish Intercollegiate Guidelines Network. Guideline on the management of asthma. Thorax 2003;58(Suppl I).

2 National Institutes of Health. Global strategy for asthma management and prevention. NIH publication No 02-3659. NHLBI Workshop Report, 2002. 3 National Asthma Council. Asthma management handbook. 2002. 
4 Barnes PJ, Pedersen S, Busse WW. Efficacy and safety of inhaled corticosteroids. Am J Respir Crit Care Med 1998;157:S1-53.

5 Suissa S, Ernst P. Inhaled corticosteroids: impact on asthma morbidity and mortality. J Allergy Clin Immunol 2001;107:937-44.

6 Adams N, Bestall J, Jones PW. Inhaled fluticasone propionate for chronic asthma. In: The Cochrane Library. Issue 1. Oxford: Update Publications, 2002.

7 Adams N, Bestall J, Jones PW. Budesonide for chronic asthma in children and adults. In: The Cochrane Library. Issue 1. Oxford: Update Publications, 2002.

8 Adams N, Bestall J, Jones PW. Inhaled beclomethasone versus placebo for chronic asthma. In: The Cochrane Library. Issue 1. Oxford: Update Publications, 2002.

9 Holt S, Suder A, Wetherall M, et al. Dose-response relation of inhaled fluticasone propionate in adolescents and adults with asthma: a meta-analysis. BMJ 2001;323:253-6.

10 Powell H, Gibson PG. Inhaled corticosteroid doses in asthma: an evidencebased approach. Med J Aust 2003;178:223-5.

11 Black PN, Lawrence BJ, Goh KH, et al. Differences in the potencies of inhaled steroids are not reflected in the doses prescribed in primary care in New Zealand. Eur J Clin Pharmacol 2000;56:431-5.

12 Todd GR, Acerini CL, Buck JJ, et al. Acute adrenal crisis in asthmatics treated with high-dose fluticasone propionate. Eur Respir J 2002;19:1207-9

13 New Zealand Guideline Group. Best practice evidence-based guidelines: the diagnosis and treatment of adult asthma. Enigma Publishing, 2003

14 Powell H, Gibson PG. High dose versus low dose inhaled corticosteroid as initial starting dose for asthma in adults and children (Cochrane Review). In: The Cochrane Library. Issue 2. Oxford: Update Publications, 2004.

15 Jadad AR, Moore RA, Carroll D, et al. Assessing the quality of reports of randomized clinical trials: is blinding necessary? Controlled Clinical Trials 1996;17:1-12

16 Campbell LM, Gooding TN, Aitchison WR, et al. Initial loading (400 micrograms twice daily) versus static ( 400 micrograms nocte) dose budesonide for asthma management. PLAN Research Group. Int $J$ Clin Pract 1998;52:361-8, 370.

17 Chanez P, Karlstrom R, Godard P. High or standard initial dose of budesonide to control mild-to-moderate asthma? Eur Respir J 2001;17:856-62.
18 Jatakanon A, Kharitonov S, Lim S, et al. Effect of differing doses of inhaled budesonide on markers of airway inflammation in patients with mild asthma. Thorax 1999;54:108-14.

19 Lorentzson S, Boe J, Eriksson G, et al. Use of inhaled corticosteroids in patients with mild asthma. Thorax 1990:45:733-5.

20 Majima T, Katoh H, Yoshida N, et al. Effects of high doses of beclomethasone dipropionate in bronchial asthma. Arerugi 1993;42:534-40.

21 Miyamoto T, Takahashi T, Nakajima S, et al. A double-blind, placebocontrolled dose-reponse study with budesonide turbuhaler in Japanese asthma patients. Respirology 2000;5:247-56.

22 Miyamoto T, Fujino S, Nakajima S, et al. Cost-effectiveness of budesonide turbuhaler in the treatment of mild-to-moderate asthma in Japan. Allergol Int 1999;48:275-85.

23 Noonan MJ, Chervinsky P, Wolfe J, et al. Dose-related response to inhaled fluticasone propionate in patients with methacholine-induced bronchial hyperresponsiveness: a double-blind, placebo-controlled study. J Asthma 1998;35: 153-64

24 O'Byrne P, Cuddy L, Taylor DW, et al. Efficacy and cost benefit of inhaled corticosteroids in patients considered to have mild asthma in primary care practice. Can Respir J 1996:3:169-75.

25 Pedersen B, Dahl R, Karlstrom R, et al. Eosinophil and neutrophil activity in asthma in a one-year trial with inhaled budesonide. The impact of smoking Am J Respir Crit Care Med 1996;153:1519-29.

26 Pirozynski M, Kulaga Z, Karstrom R. Pulmicort (budesonide) Turbohaler in mild to moderate asthma: comparison of initial high dose, constant low dose and placebo. Am J Respir Crit Care Med 1996;153:A343.

27 Sheffer AL, LaForce C, Chervinsky $\mathrm{P}$, et al. Fluticasone propionate aerosol: efficacy in patients with mild to moderate asthma. J Fam Pract 1996:42:369-75.

28 van der Molen T, Meyboom-de Jong B, Mulder HH, et al. Starting with a higher dose of inhaled corticosteroids in primary care asthma treatment. Am J Respir Crit Care Med 1998;158:121-5.

29 Wasserman SI, Gross GN, Schoenwetter WF, et al. A 12 week dose-ranging study of fluticasone propionate powder in the treatment of asthma. J Asthma 1996;33:265-74

30 O'Byrne PM, Barnes PJ, Rodriguez-Roisin R, et al. Low dose inhaled budesonide and formoterol in mild persistent asthma: the OPTIMA randomized trial. Am J Respir Crit Care Med 2001;164:1392-7.

\section{LUNG ALERT}

\section{Air pollution hampers teenagers' lung development}

$\Delta$ Gauderman WJ, Avol E, Gilliland F, et al. The effect of air pollution on lung development from 10 to 18 years of age. N Engl J Med 2004;351:1057-67

$\mathrm{T}$ he Children's Health Study recruited 1759 children from schools in Southern California and prospectively followed up these children from the age of 10 to 18 years, measuring lung function annually. FVC, $\mathrm{FEV}_{1}$, and maximal mid expiratory flow rate (MMEF) were used as markers of lung development. Air pollution monitoring stations were established in target areas that recorded pollution data continuously over the 8 years. Linear regression models were used to adjust for confounding variables and to determine the effects.

The results showed a strong association between decreased lung function $\left(\mathrm{FEV}_{1}\right)$ attained at the age of 18 years and pollutants like nitrogen dioxide $(p=0.005)$, acid vapour $(\mathrm{p}=0.01)$, fine particulate matter $\mathrm{PM}_{2.5}(\mathrm{p}=0.002)$, and elemental carbon $(\mathrm{p}=0.006)$. The effect of these pollutants was similar in both sexes and remained significant in children with no history of asthma or exposure to smoking. The authors noted that reduced lung function was a risk factor for complications and death during adulthood and later in life.

The study did not provide a mechanism for air pollutant effect, although the authors have suggested airway inflammation. It is also interesting and somewhat in contrast with the previous studies that this study has not implicated ozone in having any health effect on lung development. However, the authors point out the need for caution in interpreting this particular finding.

A Khan

Specialist Registrar in Respiratory Medicine, Derriford Hospital, Plymouth, UK; iyazkhan@aol.com 